\title{
Adsorption kinetics and isotherm of methylene blue by thermally treated alum-based water treatment plant sludge
}

Soleha Mohamat Yusuff ${ }^{1}$, Ong Keat Khim ${ }^{2, *}$, Wan Md Zin Wan Yunus ${ }^{3}$, A. Fitrianto ${ }^{4}$, M. B. Ahmad ${ }^{5}$, N. A. Ibrahim ${ }^{5}$, Mohd Junaedy Osman ${ }^{2}$, Teoh Chin Chuang ${ }^{6}$

\author{
${ }^{1}$ Department of Defence Science, Faculty of Defence Science and Technology, Universiti Pertahanan Nasional Malaysia, Kem \\ Sungai Besi, 57000, Kuala Lumpur, Malaysia \\ 2Department of Chemistry and Biology, Centre for Defence Foundation Studies, Universiti Pertahanan Nasional Malaysia, Kem \\ Sungai Besi, 57000, Kuala Lumpur, Malaysia \\ ${ }^{3}$ Department of Science and Technology Defense, Universiti Pertahanan Nasional Malaysia, Kem Sungai Besi, Sungai Besi, 57000 , \\ Kuala Lumpur, Malaysia \\ ${ }^{4}$ Department of Mathematics, Faculty of Science, Universiti Putra Malaysia, 43400 UPM Serdang, Selangor, Malaysia \\ ${ }^{5}$ Department of Chemistry, Faculty of Science, Universiti Putra Malaysia, 43400 UPM Serdang, Selangor, Malaysia \\ ${ }^{6}$ Engineering Research Centre, Malaysian Agricultural Research and Development Institute Headquarter, G. P.0. Box 12301 \\ 50774 Kuala Lumpur, Malaysia
}

\section{A R T I C LE INFO}

\section{Article history:}

Received 28 February 2017

Received in revised form

10 September 2017

Accepted 15 October 2017

Keywords:

Alum-based water treatment plant

sludge

Kinetics

Isotherm

Thermally treated

Sorption

Methylene blue

\begin{abstract}
A B S T R A C T
This paper describes the sorption kinetic and isotherm of methylene blue (MB) by thermally treated alum sludge (TAS) at the laboratory scale. Kinetics study was conducted by varying initial concentrations of MB (50, 150 and $250 \mathrm{mg} / \mathrm{L})$ and contact time (30, 60, 120 and $180 \mathrm{~min})$ whereas adsorption isotherm was investigated at various initial concentrations $(10,50,100,200$, 300 and $400 \mathrm{mg} / \mathrm{L})$ at constant temperature $\left(25^{\circ} \mathrm{C}\right)$, contact time and agitation speed. Lagergren, Ho and Mckay and intra-particle diffusion kinetics modes were applied to the experimental data while the adsorption isotherms are described by Langmuir and Freundlich and Temkin isotherm models. The results showed that sorption kinetics and isotherm of MB were best described by Ho and Mckay kinetics model and Langmuir isotherm model, respectively. The maximum adsorption capacity $\left(q_{m}\right)$ obtained from Langmuir plot was $25.445 \mathrm{mg} / \mathrm{g}$. It can be concluded the adsorption of MB by TAS is monolayer adsorption.
\end{abstract}

(C) 2017 The Authors. Published by IASE. This is an open access article under the CC BY-NC-ND license (http://creativecommons.org/licenses/by-nc-nd/4.0/).

\section{Introduction}

There is an increasing in disposal of hazardous organic compounds into the environment (Aksu, 2005). Wastewaters contaminated by synthetic dyes such as methylene blue (MB) are dangerous to human and environment as this pollutant may cause critical diseases to human and the intense color of dyes will interrupt the photosynthesis process (Crini, 2006). Therefore, reducing the synthetic dyes concentration to the safety limit in the effluent of the wastewater is highly required. The decolorization of dye by adsorption using cheap and abundantly available solid adsorbents is the flexible and costeffective method. Nevertheless, the hazardous limits of the adsorbents are also highly concerns due to

\footnotetext{
* Corresponding Author.

Email Address: ongkhim@upnm.edu.my (O. K. Khim) https://doi.org/10.21833/ijaas.2017.012.018

2313-626X/C 2017 The Authors. Published by IASE.

This is an open access article under the CC BY-NC-ND license

(http://creativecommons.org/licenses/by-nc-nd/4.0/)
}

their impacts on the environment (Ahmed, 2016). Large amount of residual sludge is generated from drinking water processing systems which cause decreasing of landfill (Babatunde and Zhao, 2007). Reuses of water treatment plant sludge for adsorptions of heavy metals (Zhou and Haynes, 2011), phosphorus (Babatunde and Zhao, 2010) and sulphur dioxide gas (Sirisha et al., 2012) have been reported. Reusing of waste materials as adsorbents for example water treatment plant sludge could be a good alternative for removal of dyes. Md Nor et al. (2014) have applied dewatered alum sludge to remove Remazol blue $\mathrm{R}$ dye, which is a cationic dye.

Various techniques have been used for modification or treatment of adsorbents to increase the adsorption capacity. Conventional heating or microwave heating will strongly affect the physical and chemical properties of a material (Ahmed, 2016). Consequently, numerous researches have applied this simple technique to modify adsorbent to increase the uptake of sorbate via chemisorption, physisorption, ion exchange, complexation or 
physico-chemisorption interactions (Smiljanić et al., 2010; Kapnisti et al., 2015).

The aim of this study is to investigate adsorption kinetics and isotherm of MB by thermally treated alum-based (TAS) water treatment plant sludge. Kinetics models of Lagergren (1898), Ho and McKay (1999), and intra-particle diffusion, and isotherm models of Langmuir, Freundlich and Temkin (LevyaRamos et al., 1995) were employed to evaluate the adsorption data.

\section{Materials and methods}

\subsection{Preparation of adsorbents}

Drinking water plant sludge cake was obtained from a local drinking water treatment plant. It was dried at $105^{\circ} \mathrm{C}$ for $24 \mathrm{~h}$, cooled to room temperature, crushed and ground by a mortar. Then, the dried sludge was heated at $800{ }^{\circ} \mathrm{C}$ for $7 \mathrm{~h}$ in a muffle furnace, cooled to room temperature and sieved to particle size between 100 to $150 \mu \mathrm{m}$.

\subsection{Preparation of adsorbate}

MB stock solution (1000 mg/L) was prepared by dissolving accurate amount of MB (3, 9-bis dimethylaminophenazo thionium chloride) (Merck, Germany) in ultrapure water. Different concentrations $(10,50$, $100,200,300$, and $400 \mathrm{mg} / \mathrm{L}$ ) of MB solutions were prepared by dilution using ultrapure water. pHs of the solutions were adjusted to $\mathrm{pH} 10$ using $0.1 \mathrm{M}$ of $\mathrm{NaOH}$ solution.

\subsection{Adsorption kinetics and isotherm}

For adsorption kinetic study, various contact time $(30,60,120$ and $180 \mathrm{~min})$ and initial concentrations of MB (50, 150 and $250 \mathrm{mg} / \mathrm{L}$ ) were employed, while for adsorption isotherm study, initial concentrations of MB were varied from 10,50,100, 200, 300 and $400 \mathrm{mg} / \mathrm{L}$ was applied at $180 \mathrm{~min}$ of contact time.

The equilibrium adsorption was performed in $250 \mathrm{~mL}$ Erlenmeyer flasks containing $0.1 \mathrm{~g}$ of thermally treated alum-based water treatment plant sludge (TAS) and $20 \mathrm{~mL}$ of $\mathrm{MB}$ solution (prior adjusted to $\mathrm{pH} 10$ ) with desired concentration. The mixture was agitated in a water bath shaker with a speed of $180 \mathrm{rpm}$ at $25^{\circ} \mathrm{C}$. Subsequently, the mixture was filtered using a Whatman filter paper No. 3 . Concentration of MB in the filtrate was determined by UV-VIS spectrophotometer at the absorption wavelength of $665 \mathrm{~nm}$. All the adsorption experiments were conducted in duplicates. The amount of methylene blue adsorbed per unit mass of TAS i.e. adsorption capacity was calculated using Eq. 1.

$q=\frac{\left(C_{i}-C_{f}\right) \times V}{m}$

where $C_{i}(\mathrm{mg} / \mathrm{L})$ and $C_{f}(\mathrm{mg} / \mathrm{L})$ are initial and final concentrations of $\mathrm{MB}$, respectively, $V(\mathrm{~L})$ is the volume of MB solution, and $m(\mathrm{~g})$ is the amount of TAS used. Finally, the data was fitted into Langmuir, Freundlich, and Temkin (Levya-Ramos et al., 1995) models.

\section{Results and discussion}

\subsection{Adsorption study}

To investigate the adsorption kinetics of MB by TAS, Lagergren (1898), Ho and McKay (1999), and intra-particle diffusion models were used to evaluate the experimental data.

Lagergren (1898) kinetics model: The linear equation form of the Lagergren (1898) model is described as follows (Eq. 2):

$\log \left(q_{t}-q_{e}\right)=\log \left(q_{e}\right)-\frac{k_{l}}{2.303} t$

where $q_{t}\left(\mathrm{mg}^{-\mathrm{g}^{-1}}\right)$ is the adsorption capacity at time $\mathrm{t}$, $\mathrm{qe}_{\mathrm{e}}\left(\mathrm{mg}^{\mathrm{g}} \mathrm{g}^{-1}\right)$ is the adsorption capacity at equilibrium time, $\mathrm{k}_{1}$ is the Lagergren (1898) rate constant (min$\left.{ }^{1}\right)$. The $\log \left(q_{t}-q_{e}\right)$ versus $t$ plot was employed to calculate the constant of Lagergren (1898) kinetics model and presented in Table 1.

\subsection{Ho and Mckay kinetics model}

Eq. 3 shows the Ho and McKay (1999) linear equation.

$\frac{t}{q_{t}}=\frac{1}{k_{2} q_{e}^{2}}+\frac{t}{q_{e}}$

where $q_{t}\left(\mathrm{mg}^{-1} \mathrm{~g}^{-1}\right)$ is the adsorption capacity at time $t$, $q_{e}\left(\mathrm{mg} \cdot \mathrm{g}^{-1}\right)$ is the adsorption capacity at equilibrium time, $k_{2}\left(\mathrm{~g} \cdot \mathrm{mg}^{-1} \mathrm{~min}^{-1}\right.$ ) is the Ho and McKay (1999) rate constant. The kinetics parameter of $\mathrm{Ho}$ and McKay (1999) was calculated from the plot of t/qt versus $t$ for the adsorption of MB by TAS.

Intra-particle diffusion kinetics model: The intraparticle diffusion kinetics model (Eq. 4) could determine the steps that controlled the rate of the adsorption process which include (a) molecular diffusion from the bulk solution to a film layer surrounding the adsorbent particle; (b) diffusion from the film to particle surface; (c) migration inside the adsorbent particle; and (d) adsorption uptake (chemisorption, physisorption, ion exchange or complexation interaction). Ghasemi et al. (2016) suggested that the rate of the adsorption process is controlled by the slowest step (Ghasemi et al., 2016).

$q_{t}=k_{d} t^{1 / 2}+C$

where $q_{t}\left(\mathrm{mg}^{-1}\right)$ is the adsorption capacity at time $t$, $k_{d}$ (mg. $\mathrm{g}^{-1} \mathrm{~min}^{-0.5}$ ) is the intra-particle diffusion rate constant and $\mathrm{c}$ is the intercept. The constant of the intra-particle diffusion kinetics and intercept were determined from the plot of $q_{t}$ versus $t^{1 / 2}$.

Table 1 shows the constants obtained from the kinetics equations ( 2 to 4 ). Figs. 1, 2 and 3 show the experimental data evaluated by Lagergren (1898), 
Ho and McKay (1999) and Intra-particle diffusion equations, respectively. The results revealed that experimental data was best fitted into Ho and McKay (1999) kinetics model as indicated by the highest $\mathrm{R}^{2}$ values. Besides that, the calculated adsorption capacity by Ho and McKay (1999) model is close to experimental adsorption capacity which is 25.90 mg.g- ${ }^{-1}$.

Table 1: Parameters of adsorption kinetics of MB by TAS

\begin{tabular}{ccccc}
\hline \multirow{2}{*}{ Model } & \multirow{2}{*}{ Parameter } & \multicolumn{3}{c}{ Concentration $(\mathrm{mg} / \mathrm{L})$} \\
\cline { 3 - 5 } & & 50 & 150 & 250 \\
\hline Lagergren & $\mathrm{k}_{1}\left(\mathrm{~min}^{-1}\right)$ & 0.0387 & -0.0276 & -0.0309 \\
(1898) & $\mathrm{R}^{2}$ & 0.4306 & 0.9833 & 0.9653 \\
Ho and & $k_{2}\left(\mathrm{~g} \cdot \mathrm{mg}^{-}\right.$ & 0.3174 & 0.0019 & 0.0019 \\
McKay & $\left.{ }^{1} \mathrm{~min}^{-1}\right)$ & & & \\
(1999) & $\mathrm{R}^{2}$ & 1.000 & 0.9928 & 0.9988 \\
Intra- & $k_{d}\left(\mathrm{mg}^{-}-\right.$ & 0.0073 & 0.7923 & 0.8856 \\
particle & $\left.{ }^{1} \mathrm{~min}^{-0.5}\right)$ & & & \\
diffusion & $\mathrm{R}^{2}$ & 0.9280 & 0.9665 & 0.9861 \\
\hline
\end{tabular}

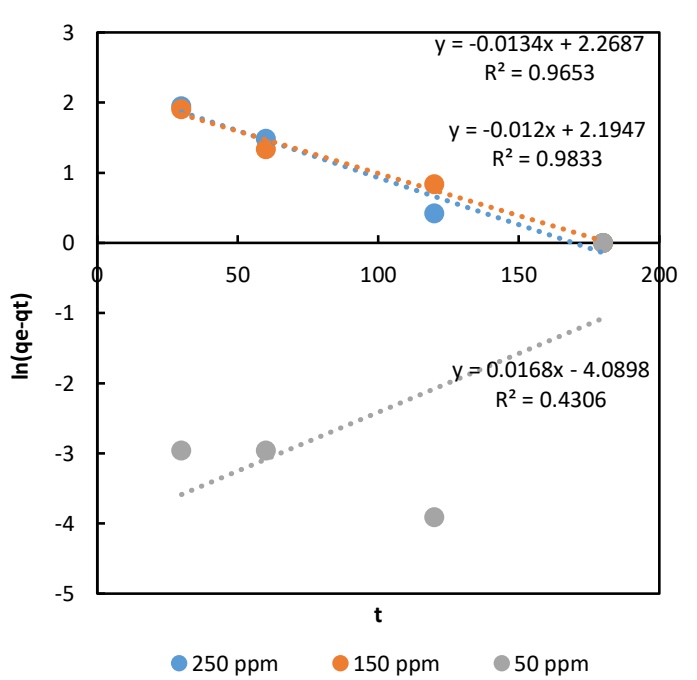

Fig. 1: Lagergren (1898) plot for adsorption of MB by TAS

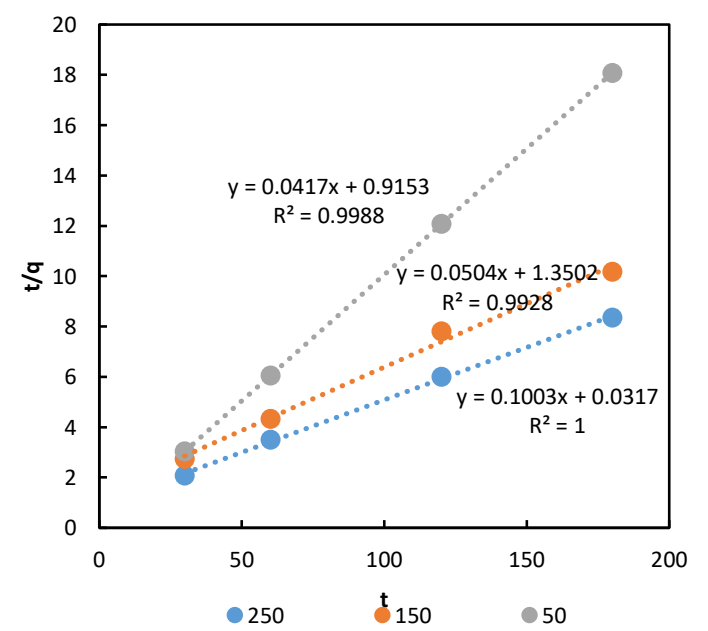

Fig. 2: Ho and McKay (1999) plot for adsorption of MB by TAS

\subsection{Adsorption isotherms}

The isotherm models of Langmuir, Freundlich and Temkin (Levya-Ramos et al., 1995) were used to investigate the adsorption capacity and examined the abilities of the isotherm models to accurately describe the adsorption process.
Langmuir isotherm model: This isotherm model suggests the monolayer adsorption of sorbate molecules on a homogeneous surface of sorbent with a finite number of adsorption sites, without any interaction between adsorbed molecules (Agarwal et al., 2016). Eq. 5 shows the linear form of Langmuir isotherm model:

$\frac{C_{e}}{q_{e}}=\frac{C_{e}}{q_{m}}+\frac{1}{q_{m} K_{L}}$

where $C_{e}(\mathrm{mg} / \mathrm{L})$ is the equilibrium concentration of methylene blue, $q_{e}(\mathrm{mg} / \mathrm{g})$ is the amount of methylene blue at equilibrium, $q_{m}(\mathrm{mg} / \mathrm{g})$ is the Langmuir constant related to adsorption capacity and $K_{L}(\mathrm{~L} / \mathrm{mg})$ is the Langmuir constants related to adsorption energy.

To explain the characteristics and feasibility of Langmuir isotherm, the equilibrium parameter $\left(\mathrm{R}_{\mathrm{L}}\right)$ value is necessary to evaluate the adsorption feasibility. The $\mathrm{R}_{\mathrm{L}}$ value may become larger than 1 , equal to 1 , equal to 0 and in range of 1 to 0 , showing that the adsorption is unfavorable, linear, irreversible and favorable, respectively (Agarwal et al., 2016).

$R_{L}=\frac{1}{1+K_{L} C_{i}}$

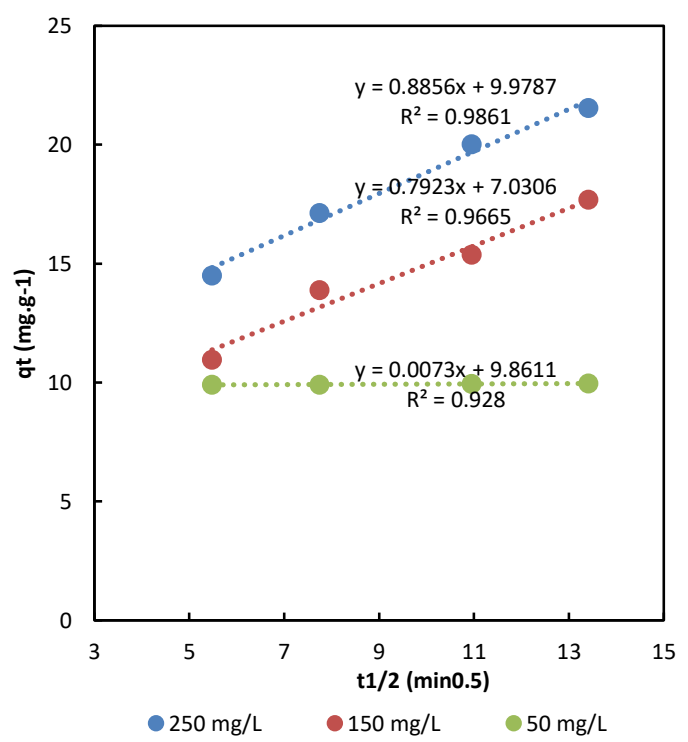

Fig. 3: Intra-particle diffusion kinetics plots for adsorption of MB by TAS

\subsection{Freundlich isotherm model}

The Freundlich isotherm assumes the multilayer adsorption of sorbate molecules on heterogeneous surface of sorbent with non-uniform distribution of adsorption heat and affinities (Agarwal et al., 2016). The linear equation form of Freundlich isotherm model is represented by Eq. 7 .

$\log q_{e}=\log k_{f}+\frac{1}{n} \log C_{e}$

where $k_{f}$ is the adsorption capacity, $1 / \mathrm{n}$ is the adsorption intensity. The $n$ value indicates the favorable adsorption if $n$ value is larger than 1 . 


\subsection{Temkin isotherm model}

This isotherm model assumes that heat of adsorption (function of temperature) of all molecules in the layer would decrease linearly with surface coverage. The linear equation form of Temkin isotherm model is represented in Eq. 8 (Dada et al., 2012).

$q_{e}=\frac{R T}{b} \ln A_{T}+\frac{R T}{b} \ln C_{e}$
$B=\frac{R T}{b}$

where $A_{T}(\mathrm{~L} / \mathrm{mg})$ is the equilibrium binding constant corresponding to the maximum binding energy, $B$ $(\mathrm{kJ} / \mathrm{mol})$ is the Temkin constant related to the heat of sorption, $T(\mathrm{~K})$ is the absolute temperature and $R$ $\left(8.314 \times 10^{-3} \mathrm{~kJ} / \mathrm{mol} . \mathrm{K}\right)$ is the gas constant.

The experimental data was evaluated by the isotherm models. Table 2 presents the constants obtained from the equations while Fig. 4, 5 and 6 show the plots of the Langmuir, Freundlich and Temkin isotherm models (Levya-Ramos et al., 1995), respectively.

The results revealed that the experimental data was best fitted by Langmuir isotherm model as indicated by the highest $R^{2}$ value (0.9721). Therefore, the adsorption of MB by TAS is monolayer adsorption. The value of $R_{L}$ was 0.0516 which is between 0 and 1 , suggesting that the adsorption of MB by TAS is a favourable process.

Table 2: Parameters of adsorption isotherms of MB by TAS (Levya-Ramos et al., 1995)

\begin{tabular}{ccc}
\hline \multicolumn{2}{c}{ Isotherm } & \multicolumn{2}{c}{ Parameter } \\
\hline \multirow{4}{*}{ Langmuir } & $\mathrm{K}_{\mathrm{L}}\left({\left.\mathrm{L} \cdot \mathrm{mg}^{-1}\right)}^{-1}\right)$ & 0.0734 \\
& $\mathrm{q}_{\mathrm{m}}\left(\mathrm{mg} \cdot \mathrm{g}^{-1}\right)$ & 25.445 \\
& $\mathrm{R}^{2}$ & 0.9721 \\
Freundlich & $\mathrm{R}_{\mathrm{L}}$ & 0.0516 \\
& $\mathrm{~K}_{\mathrm{f}}\left(\mathrm{mg} \cdot \mathrm{g}^{-1}\right)$ & 28.074 \\
& $\mathrm{n}$ & 2.917 \\
Temkin & $\mathrm{R}^{2}$ & 0.8879 \\
& $\mathrm{~B}\left(\mathrm{~kJ} / \mathrm{mol}^{-1}\right.$ & 3.2527 \\
& $\mathrm{~A}_{\mathrm{T}}\left(\mathrm{L}_{\mathrm{mg}} \mathrm{mg}^{-1}\right)$ & 6.0052 \\
& $\mathrm{R}^{2}$ & 0.9504
\end{tabular}

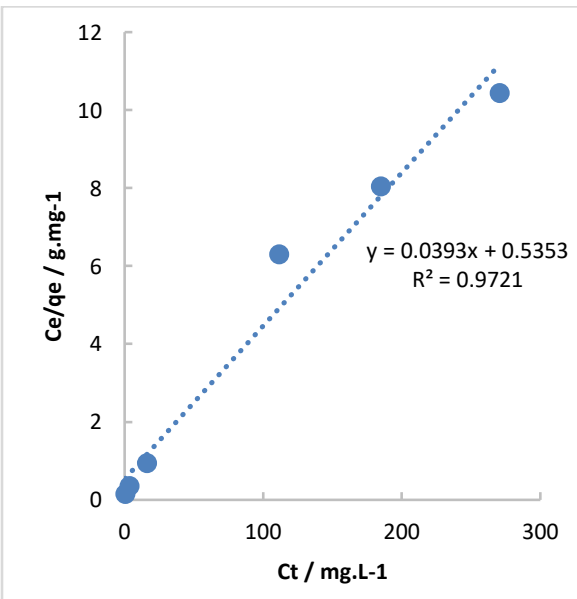

Fig. 4: Langmuir isotherm plot for adsorption of MB using TAS

\section{Conclusion}

In this study, the kinetics and isotherm adsorption of MB by TAS were investigated. The kinetic adsorption complied well with Ho and McKay (1999) kinetics model as indicated by the highest $\mathrm{R}^{2}$ value. Langmuir isotherm model produced the best for equilibrium data with the $q_{\max }$ of $25.445 \mathrm{mg} / \mathrm{g}$, and it can be said that the adsorption of MB by TAS is a monolayer adsorption process.

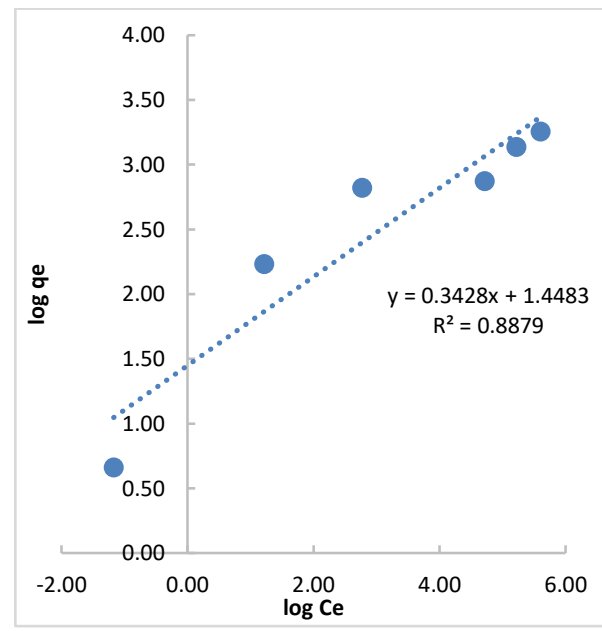

Fig. 5: Freundlich isotherm plot for adsorption of MB using TAS

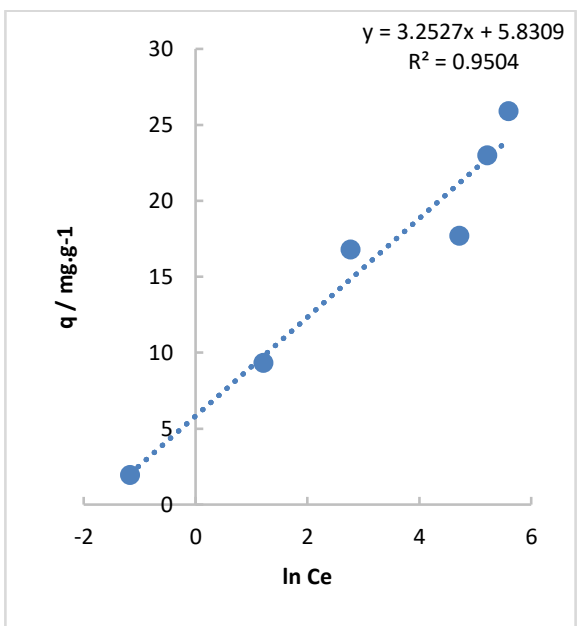

Fig. 6: Temkin isotherm model plot for adsorption of MB using TAS

\section{Acknowledgment}

The authors gratefully acknowledge supporting this study by Universiti Pertahanan Nasional Malaysia. The authors also wish to thank the ABASS Konsortium Sdn Bhd water treatment plant, Malaysia, for providing the alum-based water treatment plant sludge for this study.

\section{References}

Agarwal S, Tyagi I, Gupta VK, Ghasemi N, Shahivand M, and Ghasemi M (2016). Kinetics, equilibrium studies and thermodynamics of methylene blue adsorption on Ephedra strobilacea saw dust and modified using phosphoric acid and zinc chloride. Journal of Molecular Liquids, 218: 208-218. 
Ahmed JM (2016). Application of agricultural based activated carbons by microwave and conventional activations for basic dye adsorption: Review. Journal of Environmental Chemical Engineering, 4(1): 89-99.

Aksu Z (2005). Application of biosorption for the removal of organic pollutants: A review. Process Biochemistry, 40(3-4): 997-1026.

Babatunde AO and Zhao YQ (2007). Constructive approaches toward water treatment works sludge management: An international review of beneficial reuses. Critical Reviews in Environmental Science and Technology, 37(2): 129-164.

Babatunde AO and Zhao YQ (2010). Equilibrium and kinetic analysis of phosphorus adsorption from aqueous solution using waste alum sludge. Journal of Hazardous Materials, 184(1): 746-752.

Crini G (2006). Non-conventional low-cost adsorbents for dye removal: A review. Bioresource Technology, 97(9): 10611085.

Dada AO, Olalekan AP, Olatunya AM, and Dada O (2012). Langmuir, Freundlich, Temkin and Dubini-Radushkevich Isotherms studies of equilibrium sorption of $\mathrm{Zn}^{2+}$ unto phosphoric acid modified rice husk. Journal of Applied Chemistry, 3(1): 38-45.

Ghasemi M, Mashhadi S, Asif M, Tyagi I, Agarwal S, and Gupta VK (2016). Microwave-assisted synthesis of tetraethylenepentamine functionalized activated carbon with high adsorption capacity for Malachite green dye. Journal of Molecular Liquids, 213: 317-325.
Ho YS and McKay G (1999). Pseudo-second order model for sorption processes. Process Biochemistry, 34(5): 451-465.

Kapnisti MG, Noli FG, Arvanitiis J, and Hatzidimitriou AG (2015). Thermally modified molybdenum oxide as a potential sorbent for the removal of metal cations from aqueous solutions. Journal of Radioanalytical and Nuclear Chemistry, 307(1): 555-565.

Largergren S (1898). Zur theorie der sogenannten adsorption geloster stoffe. Kungliga Svenska Vetenskapsakademiens. Handlingar, 24(4): 1-39.

Leyva-Ramos R, Fuentes-Rubio L, Guerrero-Coronado RM, and Mendoza-Barron J (1995). Adsorption of trivalent chromium from aqueous solutions onto activated carbon. Journal of Chemical Technology and Biotechnology, 62(1): 64-67.

Md Nor MA, Ong KK, Mohamad S, Ahmad Nasaruddin NA, Jamari NLA, Wan Yunus WMZ (2014). Kinetic study of a cationic dye adsorption by dewatered alum sludge. Materials Research Innovations, 18 (Sup6): 140-143.

Sirisha D, Mukkanti K, and Gandhi N (2012). Adsorption studies on alum sludge. Advances in Applied Science Research, 3(5): 3362-3366.

Smiljanić S, Smičiklas I, Perić-Grujić A, Lončar B, and Mitrić M (2010). Rinsed and thermally treated red mud sorbents for aqueous $\mathrm{Ni}^{2+}$ ions. Chemical Engineering Journal, 162(1): 7583.

Zhou YF and Haynes RJ (2011). Removal of Pb(II), Cr(III) and $\mathrm{Cr}(\mathrm{VI})$ from aqueous solutions using alum-derived water treatment sludge. Water, Air, and Soil Pollution, 215(1): 631643. 